\title{
A influência do comércio exterior na configuração da hierarquia portuária no Senegal: processos de concentração e exclusão na periferia da economia global (1880-1939)
}

\author{
Daniel Castillo Hidalgo ${ }^{[1]}$
}

\begin{abstract}
Resumo
As cidades portuárias do Sul Global foram elementos-chave na introdução de seus hinterlands nos fluxos econômicos da globalização desde o último terço do século XIX. No caso do Senegal, a tendência é similar, revelando como a hierarquia urbana se deslocou para os portos oceânicos, expressando o maior grau de extroversão econômica. A evolução do comércio exterior da colônia marcou os movimentos nas hierarquias urbanas, unidos ao desenvolvimento das infraestruturas de transporte. Este artigo analisa as mudanças no sistema portuário senegalês entre 1880 e 1939, período durante o qual se consolidaram as estruturas econômicas coloniais. Neste modelo, Dakar jogou um papel essencial como eixo marítimo e comercial do hinterland, atendendo a fatores de desenvolvimento e evolução (locais-globais) interconectados.
\end{abstract}

Palavras-chave: cidades portuárias; imperialismo; África Ocidental.

A influência do comércio exterior na configuração da hierarquia portuária no Senegal: processos de concentração e exclusão na periferia da economia global (1880-1939) As cidades portuárias do Sul Global foram elementos-chave na introdução de suas hinterlândias nos fluxos econômicos da globalização desde o último terço do século XIX. No caso do Senegal, a tendência é similar, revelando como a hierarquia urbana se deslocou para os portos oceânicos, expressando o maior grau de extroversão econômica. A evolução do comércio exterior da colônia marcou os movimentos nas hierarquias urbanas, unidos ao desenvolvimento das infraestruturas de transporte. Este artigo analisa as mudanças no sistema portuário senegalês entre 1880 e 1939, período durante o qual se consolidaram as estruturas econômicas coloniais. Neste modelo, Dakar jogou um papel essencial como eixo marítimo e comercial da hinterlândia, atendendo a fatores de desenvolvimento e evolução (locais-globais) interconectados.

Palavras-chave: cidades portuárias; imperialismo; África Ocidental.

External Trade and Port Hierarchy in Senegal. A case of Economic Clustering in the Global Periphery (1880-1939)

\section{Abstract}

Port-cities in the Global South were key elements in the introduction of their hinterlands into the global economic trends since the last decades of the nineteenth century. In the case of Senegal, the trend is similar and it shows how the West African urban hierarchy followed the model of extroverted economic structures. The variations of the external trade of the colony remarked these urban dynamics which were tied to the development of the transport infrastructures. This paper analyzes the changes on the Senegalese port-city hierarchy between 1880 and 1939. This period accounted the consolidation of the colonial economic structures. Under these parameters, Dakar played an important role as a gateway for its hinterland.

Key words: port-cities; imperialism; West Africa.

Commerce extérieur et évolution du système portuaire au Sénégal : processus de concéntration et exclusion dans la péripherie de l'économie globale (1880-1939)

\section{Résumé}

Les villes portuaires du Sud-Global ont été des éléments clé dans l'introductions de leurs arrières-pays aux flux de la Globalisation dès les dernières décades du XIXème siècle. Au cas du Sénégal, cette évolution c'est pareille, et on explique la manière dont l’hiérarchie urbaine s'est déplacée vers les ports océaniques, en répresentant le majeur dégrée d'extroversion économique. Donc, l'évolution du commerce extérieur a marqué les mouvements dans les hiérarchies portuaires qui étaient liées aux infrastructures du transport terrestres. Cet article analyse les changements au système portuaire sénégalais entre 1880 et 1939 où les structures économiques coloniales furent rénforcés. Dans ce modèle, Dakar jouait un rôle clé comme axis maritime et commerciale de son vaste arrière pays où les facteurs du développement (locaux-globaux) étaient interconnectés. .

Mots-clé: villes portuaires; impérialisme; Afrique Occidentale 


\section{Introdução}

incorporação do Senegal nas dinâmicas comerciais da Primeira
Globalização se produziu a partir da expansão do setor agropecuá-
rio de exportação (amendoins, goma arábica, caucho, cera, peles). O final do tráfico de escravos no Império francês a partir de 1848 pôs em dificuldades as redes comerciais tradicionais que articulavam e controlavam o funcionamento da economia senegalesa. Essa mudança estrutural afetou especialmente as elites político-econômicas africanas e os comerciantes europeus expatriados que operavam no enclave marítimo de Gorée. A crise comercial da goma arábica - principal commodity - ao norte do rio Senegal a partir da década de 1860 devido à maior pujança das produções egípcias motivou ademais a aparição e posterior expansão do amendoim como principal produto de exportação. As regiões de Thiès, Sine-Saloum, Gambia e Casamance ${ }^{1}$ se especializaram nesse cultivo, ao calor do incremento da demanda europeia por matérias-primas para a indústria (Moitt, 1992, p.27-50).

A expansão do capitalismo industrial nas regiões do Sul Global se realizou seguindo modelos de dominação e dependência promovidos pelas nações imperiais na busca e abertura de novos mercados. ${ }^{2}$ Sob esse esquema de dominação capitalista, onde o poder político e econômico residia nos centros de decisão ocidentais, as regiões periféricas jogaram um papel-chave como fornecedoras de matérias-primas e receptoras líquidas das produções industriais metropolitanas, gerando desequilíbrios estruturais do ponto de vista do desenvolvimento econômico. ${ }^{3}$

A hierarquia urbana no Senegal durante este período se caracterizou pela importância das cidades portuárias atlânticas (Saint-Louis, Gorée, Rufisque e Dakar) com uma presença importante de colonos europeus (mapa 1).

Os movimentos na importância destas cidades que se desenvolveram durante o período analisado se vinculam diretamente com o desenvolvimento do grande comércio exterior e a extensão dos setores agropecuários e mineradores de exportação (Barry e Harding, 1992). O modelo de transportes linear e de caráter extrovertido se desenvolveu de modo firme na colônia africana a partir da década de 1880, quando foram construídas as primeiras vias ferroviárias que permitiam conectar as regiões produtoras do interior com os grandes portos exportadores. ${ }^{4}$ As novas condições e dinâmica extrativa do modelo institucional colonial favoreceram a transformação forçada da realidade política,

\footnotetext{
'As regiões indicadas conformam a Senegâmbia. Neste artigo contudo se especificará cada região em separado para uma melhor identificação e descrição do funcionamento do sistema urbano-portuário atendendo a questões vinculadas às hierarquias, complementariedades e especialização de funções. 2Sobre esta questão, veja-se: Curry-Machado (2013). Para um enfoque teórico crítico, veja-se: Prashad (2013). 3Para uma aproximação deste fenômeno a partir do materialismo histórico, veja-se: Amin (2003). Joseph Stiglitz (2002) aprofundou-se também nestas matérias, observando os problemas econômicos gerados pela desigualdade e pela desregulação dos mercados no longo prazo. Sobre a implantação de instituições políticas extrativas, veja-se: Acemoglu e Robinson (2012).

${ }^{4}$ Debrie (2010, p.292-300). Sobre o desenvolvimento do sistema ferroviário no Senegal e seu impacto sobre a expansão dos setores agropecuários de exportação, veja-se: Castillo (2014a, p.174-200).
} 
social e econômica das formações sociais africanas. ${ }^{5} \mathrm{O}$ modo de implementação do sistema econômico colonial no último terço do século XIX seguiu algumas pautas comuns que se reproduziram em outros espaços: ocupação e domínio do tecido produtivo regional, expansão do setor agropecuário (monocultivos), construção de eixos de transporte linear (centros produtores-portos de evacuação) e um contexto institucional discriminatório e de forte caráter extrativo (dependência externa). ${ }^{6}$

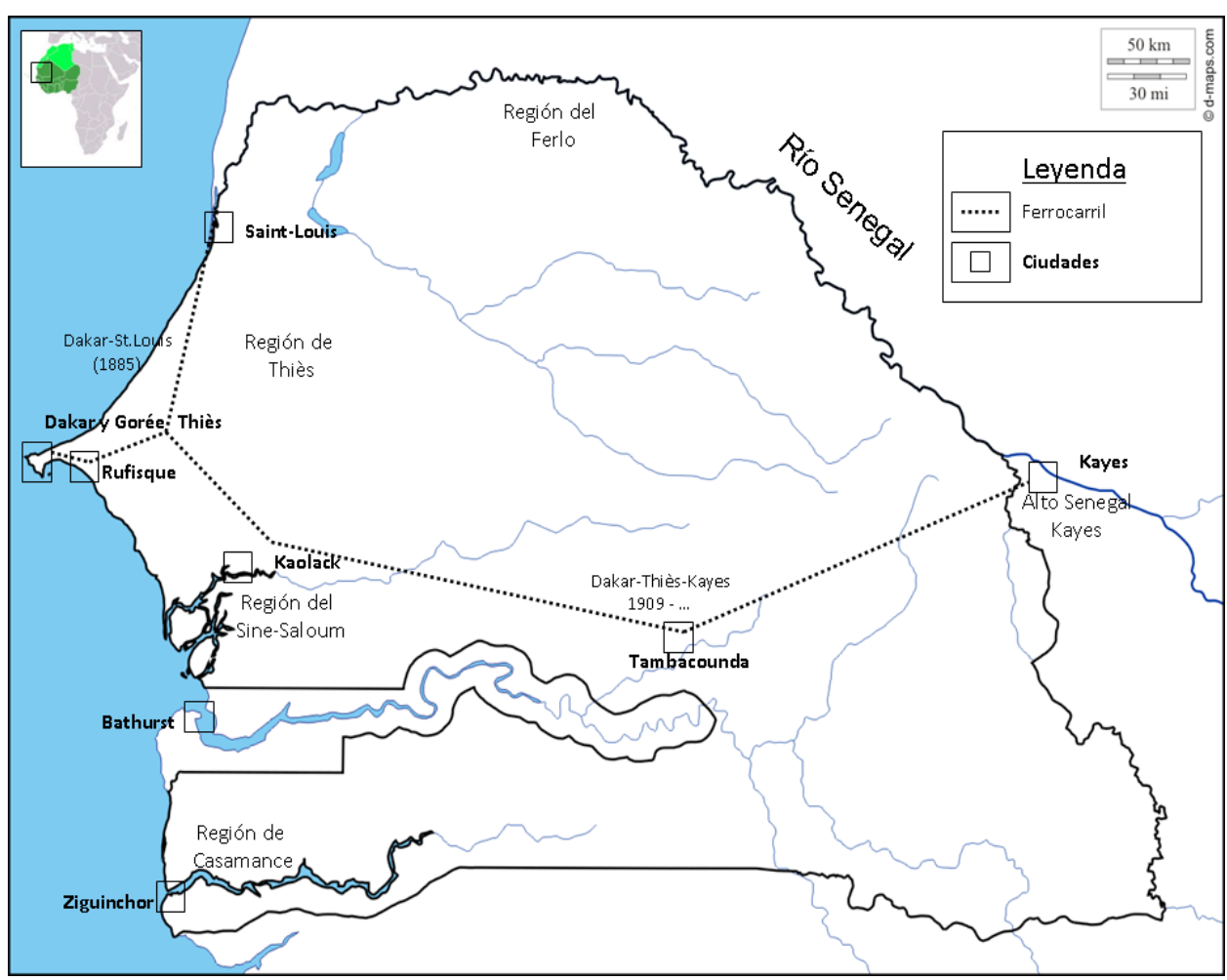

Mapa 1

Situação de Saint-Louis, Gorée, Rufisque e Dakar no Senegal (c. 1914)

Fonte: d-maps.com (acesso livre). Elaboração própria.

Este artigo analisa o caso do Senegal no contexto da primeira reforma portuária, observando a importância cada vez mais acentuada do comércio exterior nos movimentos da hierarquia urbano-portuária (Marnot, 2011). As transformações da indústria marítima (revolução técnica) aceleraram os processos de reforma das infraestruturas portuárias em escala global estimulando outros setores econômicos urbanos (economias externas portuárias, terciário portuário). No caso dos portos das regiões do sul (colônias ou territórios economicamente dependentes), essa modernização das infraestruturas as introduziu nas dinâmicas da globalização, fortalecendo diversas relações de dependência

${ }^{5}$ Acerca destas transformações, veja-se: Rodney (2011 [1. ed. de 1971]). As alterações sobre as relações laborais e a estrutura do tecido econômico no Senegal podem ser consultadas em: Fall (2011).

6eja-se: Hopkins (1969, p.580-606). Para uma revisão atual da expansão do capitalismo industrial no Golfo da Guiné, veja-se: Ayodeji (2004). 
econômica (Suárez Bosa, 2014). Este artigo estuda essa evolução em relação com os processos de urbanização e expansão da economia colonial fundamentada majoritariamente no cultivo do amendoim. Com isso, pretende-se contribuir para a tradição acadêmica que se centrou no desenvolvimento do comércio exterior colonial e nos eixos de transporte, sem atender em profundidade aos processos de desenvolvimento internos. ${ }^{7}$

A análise pormenorizada da evolução local de cada enclave portuário permite observar o funcionamento do sistema regional de portos, fundamentado no caso do Senegal na complementariedade de funções. ${ }^{8}$ A dinâmica de desenvolvimento do modelo colonial estimulou um processo de concentração da atividade econômica en Dakar, convertida na década de 1930 no principal enclave portuário da África Ocidental Francesa (AOF) em termos de atividade comercial e tráficos marítimos. O estudo da evolução particular de Dakar permite uma melhor compreensão do funcionamento de modelos econômicos extrovertidos, fundamentados na consolidação de espaços centrais (aglomeração e processos de concentração econômica) e periféricos (dependência e marginalização), em diversas escalas em nível global.

Este artigo utilizou fontes primárias procedentes dos Arquivos Nacionais Franceses de Ultramar (Anom), Arquivos Nacionais do Senegal (ANS), National Archives - Kew - (NA) e outras fontes secundárias como os Informes Consulares Britânicos (DCR), boletins comerciais, estatísticas econômicas oficiais etc.

\section{A implantação do capitalismo industrial e a transição para uma economia de mercado no Senegal: a importância de Dakar no "país do amendoim"}

Até 1857 - ano da tomada de posse oficial da península de Cabo Verde por parte da França - Dakar era um assentamento costeiro disperso, dividido em 12 aldeias africanas com uma população estimada de 12 mil pessoas. Essas comunidades se dedicavam fundamentalmente à pesca e à agricultura, unindo isto a trabalhos artesanais que complementavam a economia familiar (Charpy, 2007, p.92). Em nível político, essas aldeias se integravam em uma instituição política de entidade superior e funcionamento por assembleia, onde os representantes de cada aldeia atuavam como deputados no grande Conselho da "República Leboue" (Diouf, 2011). Essas instituições tradicionais que gerenciavam os assuntos públicos da comunidade (política exterior, distribuição de tarefas em comum, acordos comerciais) se sustentavam em concepções comunais do trabalho e dos direitos de propriedade da terra, administrados segundo critérios clientelares. $O$ trabalho em sua concepção mais ampla se vinculava ao bem-estar do grupo, adquirindo um caráter social indispensável

\footnotetext{
${ }^{7}$ A historiografia neste campo é ampla. Como exemplo, veja-se: Thomas (1957, p.1-15), Peterec (1967) Recentemente, Debrie realizou uma interessante contribuição para a melhora do conhecimento do funcionamento dos sistemas portuários na África Ocidental. Veja-se: Debrie (2012, p.1-10).

8Para uma aproximação conceitual geral do funcionamento dos sistemas portuários, veja-se: Polónia (2010, p.17-39).
} 
para o bom funcionamento da comunidade. Enquanto o trabalhador agrário era também guerreiro e defensor da comunidade, os mitos associados ao trabalho davam coesão às comunidades locais. ${ }^{9}$ A partir de 1857, essas estruturas socioeconômicas e políticas iniciaram um processo de lenta modificação para fórmulas capitalistas, onde as estruturas do modelo colonial - fundamentadas em valores modernistas - começaram a deslocar seu poder (economia de mercado, trabalho assalariado, direito positivo, individualismo). Não obstante, anteriormente à data oficial da colonização, existia uma importante comunidade de europeus expatriados em Dakar composta por comerciantes, missionários e oficiais franceses.

Nestes anos prévios à grande expansão desenvolvida durante o Segundo Império, as casas comerciais marselhesas e girondinas se encontravam fortemente instaladas nos principais núcleos costeiros da costa da África Ocidental. O velho sistema de Companhias Coloniais estava cedendo espaço a uma nova tipologia de empresa capitalista surgida no calor da revolução industrial na Europa. As demandas da indústria por matérias-primas coloniais e a suspensão do tráfico atlântico de escravos incentivaram a abertura de novos mercados, para o que era necessário um controle sobre o terreno da atividade produtiva desempenhado por agentes africanos intermediários que formavam parte de elites de poder locais. Estes, junto com os agentes europeus expatriados na África Ocidental, foram os principais dinamizadores da transição econômica regional, apoiados por consolidadas instituições coloniais (governos coloniais, conselhos da colônia, câmaras de comércio) (Barry, 1992, p.35-58).

No Senegal, as cidades costeiras de Saint-Louis, Gorée, Rufisque e Dakar aglutinaram a presença destas empresas europeias imperiais que contavam com a presença dos antigos "príncipes mercantes" africanos. As cidades atlânticas haviam sido o eixo da atividade econômica regional, especialmente no que se refere ao comércio exterior que se havia desenvolvido durante séculos vinculado ao tráfico de escravos e à exportação de goma arábica. Nesse esquema, Saint-Louis e Gorée eram os enclaves portuários mais ativos da colônia, funcionando como capital política e centro redistribuidor de mercadorias, respectivamente. As produções agropecuárias do vale do Senegal encontravam em SaintLouis um lugar de negócios para onde afluíam comerciantes do interior do país, mas também do sul da Mauritânia através das rotas de comércio do Sahel onde transitava todo tipo de mercadorias de luxo (ouro, marfim, sedas, especiarias).

No caso da pequena ilha de Gorée, sua atividade principal até 1848 havia sido a redistribuição de escravos negros para a América, conformando um empório escravista de primeira grandeza na África Ocidental. Após a proibição oficial do tráfico de escravos no Império francês, a atividade econômica da ilha entrou em crise, sendo promulgado pelo governo um decreto que a convertia em porto franco en 1852. O objetivo principal dessa medida era incrementar sua importância comercial como entrepôt regional, fortalecendo

${ }^{9}$ Sobre as mudanças ocorridas nestas considerações tradicionais, veja-se: Fall (2011). 
além disso a presença francesa na região. ${ }^{10}$ Até 1880 , Gorée foi um dos enclaves portuários mais ativos de Senegal, servindo à incipiente navegação a vapor como armazém e centro redistribuidor de commodities africanas (amendoins, goma, cera, peles, sementes), matérias-primas americanas (tabaco, açúcar) e manufaturas e produtos europeus (vinho, aguardentes, têxteis) (Castillo Hidalgo, 2015).

Não obstante, o desenvolvimento das infraestruturas portuárias no Senegal era insuficiente com respeito aos avanços que estavam sendo produzidos na indústria naval internacional (incremento do tamanho e tonelagem dos navios, transição da vela ao vapor, aumento do volume dos fluxos comerciais, incorporação da intermodalidade nos portos) (Marnot, 2011). O estado dessas infraestruturas no Senegal até a década de 1880 era muito precário, contando com alguns portos pré-industriais inapropriados para o desenvolvimento da atividade marítima contemporânea. A isso se somava a pujança dos vizinhos portos cabo-verdianos de Praia e sobretudo Mindelo (San Vicente) com uma presença britânica destacável que ameaçava a posição regional francesa. ${ }^{11} \mathrm{Em}$ nível de infraestruturas portuárias, Saint-Louis - situado na desembocadura do rio Senegal - era um enclave perigoso para a navegação devido aos depósitos sedimentários que se acumulavam durante os meses úmidos. Os navios de maior calado deviam aguardar no oceano enquanto as mercadorias e os passageiros eran transportados em embarcações auxiliares que dificultavam as operações portuárias.
La réputation de cette barre est des plus mauvaises, et les voya- geurs impatients qui ont préféré au mal de mer et à quelque temps d'attente en face de l'embouchure du fleuve les péripéties d'un petit voyage en pirogue au milieu des vagues qui grondent et déferlent, racontent avec complaisance que le gouverneur ou plutôt le directeur de la Compagnie du Sénégal, de Richebeur, s'est noyé en la passant; mais cet accident a eu lieu en 1712, et depuis, grâce à l'habileté des pilotes et du personnel du capi- taine de la barre, elle a fait peu de victimes. (Rambaud, 1893, p.238 [1. ed. de 1885])

Com respeito a Gorée, suas instalações portuárias eram escassas e suas possibilidades de expansão muito reduzidas (limitações espaciais, escassez de água, profundidade das águas, ventos e marés). O futuro da vida econômica da colônia - e da prosperidade do comércio exterior - ia ser determinado na península de Cabo Verde, nos dois enclaves que ofereciam melhores condições naturais para o desenvolvimento de um porto moderno: Rufisque e Dakar. Situadas no eixo de comunicações das grandes rotas comerciais do Atlântico Médio, sua posição lhes outorgava um controle mais efetivo do centro e do

\footnotetext{
${ }^{10} \mathrm{~A}$ outorga de franquias pretendia fortalecer as funções comerciais da ilha, convertida em entrepôt regional em 7 de janeiro de 1822, com importantes isenções fiscais que a diferenciavam do resto da colônia. Les Colonies Françaises, Le Sénégal (1900, p.287).

"Prata (2014, p.49-69). Sobre o desenvolvimento da atividade portuária em Cabo Verde, veja-se: Silva (2000). Do mesmo autor, na perspectiva da geografia econômica: Silva (2007).
} 
sul da colônia, ameaçado pela presença britânica na Gâmbia. O controle dos mercados senegaleses ante a Grã-Bretanha e o hinterland até o Sudão requeria essas bases portuárias, pontas de lança da expansão militar e econômica para o interior. O Foreign Office destacava a rivalidade franco-britânica no controle da atividade comercial regional em vésperas da Conferência de Berlim que organizou o reparte do botim africano. "Everybody seems to be agreed that the occupation of any place or river by the French is almost destructive of British trade, and that is therefore of great importance to keep them out of districts which either are or might be favourable to that trade." 12

Era necessária, ademáis, a construção de estradas de ferro que articulassem os eixos comerciais costeiros e facilitassem a expansão das redes comerciais coloniais, como destacava o engenheiro Pinet-Laprade, impulsionador das primeiras obras de planificação urbana em Dakar.

\title{
No Senegal, as cidades costeiras de Saint-Louis, Gorée, Rufisque e Dakar aglutinaram a presença destas empresas europeias imperiais que contavam com a presença dos antigos "príncipes mercantes" africanos
}

\begin{abstract}
Nous croyons donc pouvoir conclure d'une manière certaine que l'établissement d'un chemin de fer entre Sor et Dakar sera possible dans peu d'années et produira une révolution des plus heureuses dans la marche des opérations commerciales du Sénégal, tout en favorisant au plus haut degré le développement de nos établissements du Cap Vert (...) L'avenir de cette intéressante colonie dépendrait-il davantage du petit mouvement que pourraient donner à son commerce de détail les bâtiments qui entrent dans le fleuve que de la grande facilité et de l'économie que l'on introduira dans ses rapports avec l'Europe! $!^{13}$
\end{abstract}

Contudo, essa visão otimista do engenheiro francês demorou varias décadas para se realizar já que não se empreenderam obras de vulto em Dakar até a década de 1880 depois da integração ferroviária (Dakar-Saint-Louis) e da instalação de depósitos de carvão e algumas primeiras infraestruturas portuárias. Até esse momento, o porto apenas contava com um dique de abrigo (grand jetée) construído entre 1857 e 1866 para permitir as escalas de Messageries Impériales em suas travessias para Brasil e Argentina.

A reforma portuária em Dakar se inscreveu nos projetos de expansão imperial do último terço do século XIX, a que se uniu o crescimento da atividade comercial no vizinho porto de Rufisque. Situado na interseção da região produtora de amendoins de Thiès, Rufisque absorvia também os tráficos

${ }^{12}$ NA. FO. 881-4866. Informe realizado pelo oficial T.V. Lister ao Foreign Office acerca da presença francesa na África Ocidental, 24 de outubro de 1883.

${ }^{13}$ Entrevista com o engenheiro Pinet Laprade, publicada em: Les Colonies Françaises (1857, p.10-11). 
marítimos procedentes de Sine-Saloum e dos portos fluviais exportadores de Foundiougne e Kaolack. A conectividade marítima entre esses portos era muito intensa, desenvolvida em pequenos vapores ou veleiros pilotados por pessoal africano. O sistema portuário senegalês funcionou sob estes parâmetros de complementariedade de funções até a década de 1880, quando entraram em crise os velhos enclaves portuários de Saint-Louis e Gorée.

A maior importância de Dakar e Rufisque no último terço do XIX se explica pelo crescimento do comércio exterior da colônia (setores agropecuários), pelas conexões ferroviárias entre os principais portos e pelo papel cada vez mais importante da economia de mercado nas transações locais. Todas essas circunstâncias que se identificam com a introdução do capitalismo na África Ocidental não podiam desenvolver-se sem algumas infraestruturas de transporte adequadas que pareciam sim oferecer os dois novos portos emergentes - ao menos potencialmente, como destacava o cônsul britânico em Dakar em 1898: "It appears probable that Dakar is destined to hold an important position as a commercial centre and port of call, not only for Senegal, but for the whole of West Coast". ${ }^{14}$

Não obstante, Saint-Louis reteve seu poder econômico e político até a primeira década do século XX, quando se tornou manifesta a superioridade de Dakar e Rufisque. Para isso contribuiu o papel da Câmara de Comércio de SaintLouis, que operava como um grupo de pressão ante as instituições coloniais. Contudo, a importância de Dakar foi reforçada em 1888 quando se constituiu de modo independente a Câmara de Comércio de Dakar, que absorveu a de Gorée - incluindo sua aduana. Esses movimentos na hierarquia urbano-portuária de Dakar se associaram estreitamente com a expansão do amendoim como principal produto de exportação regional, submetido ao monopólio colonial francês. $\mathrm{O}$ amendoim era um produto com múltiplas aplicações na indústria metropolitana e os portos de Rufisque e Dakar deviam converter-se em suas plataformas de evacuação.

Dans l'arachide, rien ne se perd. Le fruit produit une huile grasse employé en Europe dans la confiserie, dans la savonnerie, le graissage des laines, l'éclairage, la confection des fromages de Gruyère et de Hollande, la fabrication de la margarine, etc. L'amande sert à la nourriture des bestiaux; la tige est utilisé comme fourrage aux bestiaux lorsqu'elle est fraichement coupée; desséchée, elle sert de combustible et d'engrais. Dans son intéressant ouvrage sur le Sénégal, Paul Gaffarel prétend que l'amande pourrait être utilisée dans la fabrication du chocolat en remplacement du cacao. (Lagrillière-Beauclerc, 1897, p.19)

O amendoim é o elemento-chave da implantação do modelo econômico colonial no Senegal. Sua importância capital para o comércio exterior exercia alguns efeitos de arrasto sobre o conjunto do tecido produtivo da colônia. Isso implicou que a maior parte da população agrária (paysans) se dedicasse

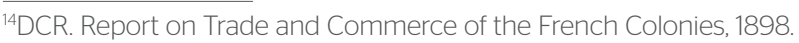


ao cultivo do amendoim como principal atividade econômica. As autoridades coloniais e as empresas imperiais apoiaram e incentivaram a extensão desse setor, favorecido por sua boa acolhida nos mercados industriais metropolitanos. As comunidades agrárias africanas (familiares, comunais ou religiosas daras) se voltaram para o cultivo desse produto que era vendido facilmente para os intermediários, enquanto as estradas de ferro se estendiam pelas regiões produtoras: "Senegal depends for its prosperity entirely on the groundnut crop, and as yet nothing has been found to take its place". ${ }^{15}$ Os critérios econômicos ricardianos estmulavam a maior dependência da economia senegalesa para esse produto, que representava uma porcentagem esmagadora das exportações (tabela 1).

Tabela 1 - Importância das exportações de amendoins sobre as exportações do Senegal (1889-1914)

\begin{tabular}{|c|c|c|c|c|c|}
\hline Año & $\begin{array}{l}\text { Cantidad } \\
\text { Exportada } \\
\text { (t) }\end{array}$ & $\begin{array}{c}\text { Valor } \\
\text { (francos) }\end{array}$ & $\begin{array}{c}\text { Total Exportaciones } \\
\text { Senegal (francos) }\end{array}$ & $\begin{array}{c}\text { \% del valor de los } \\
\text { Cacahuetes sobre las } \\
\text { Exportaciones totales }\end{array}$ & $\begin{array}{c}\text { Valor FOB } \\
\text { Exportaciones } \\
\text { Francos/tonelada }\end{array}$ \\
\hline 1889 & 31.907 & 7.558 .656 & 15.824 .019 & 47,77 & 236,90 \\
\hline 1890 & 27.221 & 5.425 .805 & 12.516 .716 & 43,35 & 199,32 \\
\hline 1891 & 26.391 & 5.479 .477 & 12.948 .328 & 42,32 & 207,63 \\
\hline 1892 & 46.790 & 11.635 .944 & 17.334 .092 & 67,13 & 248,68 \\
\hline 1893 & 59.302 & 11.688 .590 & 17.984 .730 & 64,99 & 197,10 \\
\hline 1894 & 65.289 & 11.357 .578 & 18.166 .971 & 62,52 & 173,96 \\
\hline 1896 & 51.600 & 7.675 .518 & 12.435 .888 & 61,72 & 148,75 \\
\hline 1897 & 63.556 & 9.146 .012 & 19.563 .065 & 46,75 & 143,90 \\
\hline 1898 & 58.123 & 8.336 .656 & 19.369 .350 & 43,04 & 143,43 \\
\hline 1899 & 95.555 & 13.615 .059 & 23.546 .425 & 57,82 & 142,48 \\
\hline 1900 & 140.922 & 24.200 .000 & 29.964 .142 & 80,76 & 171,73 \\
\hline 1901 & 123.483 & 22.117 .000 & 26.334 .720 & 83,98 & 179,11 \\
\hline 1902 & 110.225 & 20.525 .000 & 25.562 .781 & 80,29 & 186,21 \\
\hline 1903 & 148.843 & 34.575 .000 & 40.630 .012 & 85,10 & 232,29 \\
\hline 1904 & 137.784 & 21.320 .000 & 29.920 .893 & 71,25 & 154,73 \\
\hline 1905 & 96.175 & 14.851 .000 & 24.564 .355 & 60,46 & 154,42 \\
\hline 1906 & 100.476 & 20.976 .000 & 35.718 .741 & 58,73 & 208,77 \\
\hline 1907 & 154.496 & 30.721 .000 & 43.858 .850 & 70,05 & 198,85 \\
\hline 1908 & 144.139 & 32.889 .000 & 45.474 .064 & 72,32 & 228,18 \\
\hline 1909 & 224.326 & 43.892 .000 & 59.164 .917 & 74,19 & 195,66 \\
\hline 1910 & 227.299 & 49770741 & 64.254 .175 & 77,46 & 218,97 \\
\hline 1911 & 164.908 & 40.943 .950 & 53.382 .425 & 76,70 & 248,28 \\
\hline 1912 & 184.762 & 41.162 .966 & 56.019 .800 & 73,48 & 222,79 \\
\hline 1913 & 229.962 & 57.278 .808 & 72.937 .825 & 78,53 & 249,08 \\
\hline 1914 & 280.527 & 69.889 .309 & 80.447 .375 & 86,58 & 249,14 \\
\hline
\end{tabular}

Fonte: Para as exportações de amendoins: de 1889 a 1909, Ndao (2009:114-115). De 1909 em diante: Gouvernement Général de l'AOF (1931). Para o comércio exterior em geral: (1881-1900), Annuaire Statistique de la France. Para 1901, NA. FO881-8050X: 1900-1915, ANS. Rapports Économiques du GGAOF. Elaboração própria.

Esta maior dependência do comércio exterior, a vulnerabilidade da estrutura econômica, o controle dos canais de distribuição e do contexto institucional por parte metropolitana e a estrutura extrovertida do sistema de transportes foram elementos que marcaram o desenvolvimento econômico do Senegal, como modelo de extração e dominação econômica (Rodney, 2011 [1. ed. de 1971]). Como se pode observar na tabela 1, o incremento do comércio exterior no Senegal na última década do século XIX responde à dinâmica dos fluxos globais e à luta imperialista que culminaria na Primeira Guerra Mundial. Esse

${ }^{15}$ DCR. No. 3543, West Africa, 1904-1905. 
crescimento econômico fundamentado no comércio exterior se desenvolveu em Rufisque e Dakar, convertidas já nos eixos da política colonial europeia onde as principais empresas imperiais situaram seus escritórios e armazéns.

À importância da expansão dos setores agropecuários de exportação se acrescentou a maior presença europeia, seja do setor privado (empresários, intermediários), seja do setor público (oficiais, funcionários, exército). Ambos os elementos são chave para compreender a transformação do tecido produtivo africano, assim como na progressiva eliminação das instituições políticas tradicionais, eclipsadas pela imposição dos modelos jurídicos metropolitanos (Hopkins, 2009, p.155-177). Essa política imperialista podia resolver-se de modo pactado com as elites locais ou através da imposição violenta por meio da eliminação física da dissidência (Barrows, 1976, p.95-117).

\section{O crescimento da importância de Dakar como cidade portuária}

A potencialidade de crescimento do porto de Dakar para converter-se em uma estação de escala e apoio à navegação no último terço do XIX foi um dos aspectos que incentivaram a consolidação dos projetos de reforma das infraestruturas. A expansão a partir de 1880 dos setores agrários de exportação no Senegal - junto com a instalação na região de Thiès da conexão ferroviária DakarSaint-Louis - requeria instalações portuárias adequadas para a articulação do comércio exterior. Sob esse modelo, os novos portos de Dakar e Rufisque deviam organizar a atividade comercial da colônia, em um momento de expansão da economia internacional, onde os velhos enclaves portuários tinham ficado obsoletos. Por sua parte, o empresariado marítimo britânico (navegadoras, carvoeiras, consignatárias) havia consolidado sua presença regional nos portos vizinhos de Cabo Verde e Canárias, onde desenvolveram o setor naval. ${ }^{16}$

Entre 1880 e 1910 se desenvolveram as principais infraestruturas de transporte da colônia, onde Dakar absorveu a maior parte das inversões. A mudança na hierarquia portuária se somou também a um incremento da importância política de Dakar, convertida em capital do AOF em 1902, e ao desenvolvimento da economia urbana: criação do Banco do AOF em 1901 com sede central em Dakar, instalação de empresas portuárias (Wilson and Sons, 1904, Le Sénégal, 1909) e comerciais, assim como um terciário portuário vinculado ao setor da hotelaria e da restauração. ${ }^{17}$ Este processo de concentração de atividades econômicas desenvolvido em Dakar em torno do porto se converteu em uma constante que gerou um efeito de atração da mão de obra regional, como se observará posteriormente. A cidade, convertida em eixo da política imperial francesa (em termos de marinha mercante e de guerra), era a ponta de lança da expansão para o interior, aglutinando com o passar dos anos uma maior

${ }^{16}$ Sobre esta questão, veja-se: Cabrera Armas (2014, p.19-48).

${ }^{17}$ Anom. 14MIOM/1455. Informe do Secretário-Geral de Primera Classe das Colônias, Albert Dubarry, 10 de maio de 1911. 
quantidade de funções urbanas. ${ }^{18}$ Esse modelo de desenvolvimento urbano caracteriza além disso as economias dependentes do sul, onde a integração nas redes econômicas globais se plasmou na estrutura dos transportes regionais. ${ }^{19}$

A ferrovia foi o outro elemento-chave para o desenvolvimento da economia colonial, fortalecendo a expansão dos cultivos agropecuários ao permitir uma interação mais rápida entre os produtores africanos e os intermediários das companhias imperiais.

Until the advent of the railway the River Senegal was the principal trade route between the coast markets and the hinterland. The coming of the Konakry-Niger has, however, changed all that, and now merchandises from the markets of the world is finding its way towards the remote interior (...) Thanks to this line [DakarSaint-Louis] the groundnut trade has developed greatly, especially in the Cayor district. ${ }^{20}$

Como indicavam os oficiais britânicos, a ferrovia permitiu substituir a escala marítima de Saint-Louis, podendo baldear-se as mercadorias procedentes do vale do Senegal até os portos exportadores de Rufisque e Dakar. A substituição de Saint-Louis como base comercial da colônia em detrimento daqueles favoreceu o desenvolvimento portuário no Senegal, especialmente após a finalização das obras do porto de comércio de Dakar em 1910. Até esse momento, Rufisque concentrou a maior parte da atividade comercial da colônia (importação-exportação), enquanto Dakar ostentava uma posição-chave como escala logística para a frota mercante e de guerra (carvoaria, reparações, abastecimento de víveres, armamento etc.). Não obstante, a importância das inversões francesas ocorridas em Dakar havia gerado uma corrente de opinião favorável à concentração de toda a atividade marítima nesse porto, questão que se consolidou na década de 1930. Isto implicava que Rufisque deixasse de participar no comércio exterior da colônia, deslocando suas atividades para o porto de Dakar. O engenheiro Albert Dubarry em seu informe de 1911 tornou clara essa questão, fundamentando-se em critérios exclusivamente econômicos (estrutura de custos agregados).

A Rufisque, la tonne d'arachide acquitte un péage de deux francs pour circuler sur les voies Decauville qui sillonnent les rues de la ville. Cette taxe qui constitue la principale recette du budget de la ville, était de trois francs lorsque la rivalité de Dakar n'était pas à craindre pour Rufisque (...) Un navire de 1.200 tonneaux met ainsi trois jours environ pour se charger à Dakar, tandis qu'il met quatre à Rufisque pour prendre une cargaison complète. L'emploi de Dakar comme port d'embarquement de l'arachide fait donc économiser deux journées de stationnement aux bateaux. ${ }^{21}$

\footnotetext{
${ }_{18}$ Sobre este processo de metropolização regional, veja-se: Seck (1970).

${ }^{19}$ Sobre estas questões, pode-se consultar a análise realizada nos países do Magreb que respondem a mecanismos extrativos similares: Mohamed-Chérif e Ducruet (2011).

${ }^{20}$ DCR. Report on Trade and Commerce. No. 5235, 1912.

${ }^{21}$ Anom. 14MIOM/1455. Informe do Secretário-Geral de Primeira Classe das Colônias, Albert Dubarry, 10 de maio de 1911.
} 
Esta decisão implicava a geração de importantes efeitos de arrasto sobre o conjunto da economia urbana, posto que um deslocamento de atividade de tal envergadura devia transformar a estrutura do empresariado local, alterando o equilíbrio de poderes regional e incrementando as disputas entre as Câmaras de Comércio de Dakar e Rufisque. Deve se destacar além disso o incremento da importância da atividade marítima em Dakar desde os inícios do século XX, que se explica entre outras questões pela melhora das infraestruturas, o crescimento do comércio exterior regional, a centralização da vida econômica da colônia em suas águas e a maior competitividade dos serviços de apoio à navegação (tabela 2).

Tabela 2 - Indicadores de atividade portuária em Dakar (1894-1929)

\begin{tabular}{lccccccc}
\hline Aĩo & $\begin{array}{c}\text { Buques } \\
\text { entrados* }\end{array}$ & TRB & $\begin{array}{c}\text { Tráfico de } \\
\text { Importación } \\
\text { (t)** }\end{array}$ & $\begin{array}{c}\text { Importación } \\
\text { de carbón(t) }\end{array}$ & $\begin{array}{c}\text { Suministro } \\
\text { de carbón (t) }\end{array}$ & $\begin{array}{c}\text { Exportación } \\
\text { suministrada (t) }\end{array}$ & $\begin{array}{c}\text { De } \\
\text { cacahuetes } \\
\text { (t) }\end{array}$ \\
\hline 1894 & 423 & 336.834 & - & 16.406 & 14.709 & - & - \\
1895 & 470 & 419.773 & - & 13.748 & 15.424 & - & - \\
1896 & 582 & 523.683 & 47.807 & 17.993 & - & - & - \\
1906 & 768 & 950.460 & 151.270 & 89.100 & 59.100 & - & - \\
1907 & 698 & 1.145 .729 & 157.249 & 99.000 & - & - & 1.004 \\
1908 & 666 & 1.172 .100 & 244.917 & 121.750 & 88.858 & 48.900 & - \\
1909 & 730 & 1.242 .870 & 148.160 & 87.461 & 93.212 & 67.454 & - \\
1910 & 982 & 1.656 .984 & 249.498 & 170.477 & 142.013 & 86.033 & 9.111 \\
1911 & 1.165 & 2.006 .621 & 295.680 & 197.615 & 197.000 & 97.572 & - \\
1912 & 1.213 & 2.270 .538 & 358.048 & 277.000 & 242.000 & 117.160 & - \\
1913 & 1.393 & 2.602 .021 & 421.949 & 313.000 & 267.000 & 84.700 & - \\
1914 & 1.111 & 2.002 .984 & 318.722 & 182.410 & 158.000 & 87.791 & - \\
1915 & 1.224 & 2.366 .716 & 325.637 & 251.348 & 214.519 & 133.721 & 6.038 \\
1916 & 1.975 & 5.675 .356 & 445.600 & 393.000 & 324.789 & 100.042 & 7.191 \\
1917 & 2.181 & 5.239 .000 & 614.349 & 544.261 & 508.600 & 160.000 & 10.793 \\
1918 & 1.399 & 3.179 .897 & 648.123 & 387.000 & 344.200 & 185.700 & 43.562 \\
1919 & 1.163 & 2.446 .208 & 404.013 & 337.000 & 294.940 & 154.300 & 49.948 \\
1920 & 1.224 & 3.080 .675 & 452.721 & 327.000 & 282.552 & 161.000 & 33.032 \\
1921 & 1.232 & 2.239 .957 & 270.295 & 199.000 & 176.500 & 118.200 & 26.282 \\
1922 & 1.992 & 2.188 .785 & 314.584 & 189.500 & 163.112 & 133.500 & 32.583 \\
1923 & 2.086 & 2.667 .799 & 322.437 & 211.985 & 163.799 & 130.000 & 42.253 \\
1924 & 2.091 & 2.919 .805 & 353.152 & 203.007 & 168.137 & 157.000 & 59.223 \\
1925 & 2.273 & 3.286 .726 & 423.655 & 228.270 & 180.000 & 181.000 & 103.391 \\
1926 & 2.225 & 3.341 .707 & 478.557 & 234.850 & 214.500 & 209.500 & 102.410 \\
1927 & 2.101 & 2.882 .027 & 418.526 & 205.910 & 157.680 & 193.800 & 64.352 \\
1928 & 3.013 & 4.626 .675 & 590.022 & 323.160 & 288.393 & 203.300 & 80.674 \\
1929 & 2.757 & 4.287 .132 & 575.367 & 276.026 & 217.838 & 237.759 & 82.527 \\
\hline
\end{tabular}

Nota: *Exclui-se o tráfico de cabotagem e de pesca **|nclui importações de carbono Fontes: Para 1894-1900; Diouf (2011, p.403); ANS. 2G7-34; Anom, 14MIOM/1455, 10/5/1911. Para 1900-18, Castillo Hidalgo (2014b, p.107). Para 1917-29: Le Gouvernement de l'AOF (1931). Elaboração própria.

A tabela 2 mostra o crescimento sustentado da atividade portuária em Dakar ao longo do período estudado, observando além disso diferentes conjunturas que impactaram o desenvolvimento da atividade marítima em escala global (expansão econômica regional prévia à Primeira Guerra Mundial, conflito mundial, crise e recuperação do período de entreguerras etc.). Dakar se converteu em um porto líder em escala regional, deslocando progressivamente 
outros portos menos competitivos como Mindelo para uma posição secundária. Nessa hierarquia portuária, as instituições francesas propuseram uma luta competitiva ante os portos das Ilhas Canárias (e especialmente o de Las Palmas), para dotar o porto senegalês de algumas infraestruturas modernas para garantir funções de apoio à navegação eficientes.

Les espagnols équipaient à Las Palmas le port de La Luz. Dans ce port, assez proche de l'Europe, le combustible était moins coûteux, et les navires trouvaient, grâce à la fertilité des Îles Canaries, des ressources en primeurs [tomates, bananas] que ne pouvaient offrir les déserts du Sénégal. Pour compenser de tels avantages naturels, le port de Dakar ne pouvait que s'assurer une nette supériorité d'outillage et de technique. (Morazé, 1936, p.611)

\section{A ferrovia foi o outro elemento-chave para o desenvolvimento da economia colonial}

Durante a primeira década do século XX, a atividade carvoeira em Dakar se incrementou de forma notável como consequência da instalação de várias companhias carvoeiras que dinamizaram a atividade marítima do porto (Wilson and Sons e a Compagnie Italienne "Sénégal"). A tabela 2 representa fielmente o incremento dos tráficos de carvão no porto (importação e fornecimento) que se vincula à atividade dessas duas empresas. Nesse mercado em expansão, Wilson and Sons (brasileiro-galesa) jogou um papel-chave, assinando diferentes acordos de fornecimento com a administração francesa, permitindo desse modo conseguir preços competitivos para o carvão fornecido em Dakar. ${ }^{22}$ Essa companhia formava parte da ponta de lança do capitalismo imperial anglo-saxão, com uma forte presença nos principais portos carvoeiros do Atlântico. ${ }^{23}$ A outra companhia que impulsionou o deslocamento portuário em Dakar foi "Le Sénégal", empresa de capital franco-italiano que consignou os navios de linha italianos que faziam escala no Senegal em suas travessias para a América do Sul desde 1909. A substituição da escala de Mindelo em 1913 para estas travessias foi um elemento-chave na absorção de importantes tráficos marítimos que elevaram a atividade do porto senegalês. ${ }^{24}$

Em consequência, os indicadores portuários experimentaram uma subida notável, vinculada às funções de escala e apoio à navegação, mas também a um crescimento sustentado da atividade comercial do porto, sobretudo na importação de maquinaria pesada, armas e outras manufaturas metropolitanas.

\footnotetext{
${ }^{22}$ NA. FO. 27/3682, Informe do comércio de carvão no Senegal realizado pelo Cônsul britânico em Dakar, 1904.

${ }^{23}$ Para uma análise precisa do funcionamento de Wilson and Sons nos portos insulares do Atlântico Médio, veja-se: Suárez Bosa e Cabrera Armas (2012, p.363-414).

${ }^{24}$ Anom. 14MIOM/1455. Informe do Secretário-Geral de Primeira Classe das Colônias, Albert Dubarry, 10 de maio de 1911.
} 
Esse movimento comercial impactou positivamente a criação de empresas do terciário portuário, assim como a maior instalação de companhias comerciais dedicadas ao comércio exterior (Grand Commerce) que incrementaram a demanda de mão de obra local (Seck, 1970, p.64-66). Desse modo, as empresas portuárias (estivadoras, consignatárias, carvoeiras) e o crescente tecido urbano vinculado ao porto de comércio geraram um processo de atração de mão de obra rural. Isso foi especialmente importante nos entornos rurais mais deprimidos pela implantação do sistema capitalista, onde os maiores salários nominais urbanos atuavam como elementos atrativos para a sustentação da economia familiar. O trabalho agrário poderia combinar-se por temporadas com a estiva nos portos ou outras funções similares (chargeurs), ajudando nas docas em temporada de exportação em busca de um jornal. Essa mobilidade dos trabalhadores africanos motivou diversas políticas de assentamento e fixação da mão de obra desde a primeira década do século XX nos arredores de Dakar. ${ }^{25}$

Mesmo assim, o grande comércio exterior continuou desenvolvendo-se em Rufisque até a década de 1930, ficando ambos os portos conectados por um intenso tráfico de cabotagem. Isso suscita a existência de um sistema portuário regional (na escala de Senegal e Gâmbia) caracterizado pela complementariedade de funções entre portos centrais e secundários que desenvolviam diversas funções (escala, grande comércio, trânsito comercial). No contexto da primeira reforma portuária, Dakar e Rufisque encabeçaram a hierarquia portuária senegalesa, substituindo os velhos enclaves que foram incapazes de adaptar-se às demandas da navegação internacional e às necessidades da economia colonial.

As mudanças na hierarquia urbano-portuária senegalesa estimularam um processo de crescimento demográfico nos núcleos marítimos mais ativos que se agudizaria na década de 1930, como será exposto posteriormente. Esse crescimento populacional implicou transformações urbanísticas, mas também importantes mudanças sociais com a aparição de classes populares urbanas nas cidades-portuárias, especialmente em Dakar. Esses novos grupos sociais urbanos formados majoritariamente por camponeses migrantes se caracterizaram por padecer duras condições de vida, associadas à precariedade laboral e à discriminação racial e política, especialmente no que se refere aos direitos trabalhistas. ${ }^{26}$ A maior parte desses trabalhadores urbanos era considerada mão de obra barata e dispensável, encarregada de tarefas básicas de carga e descarga de mercadorias por parte das empresas imperiais. Outros trabalhavam como operários de construção, peões ferroviários, artesãos e empregados nas casas comerciais, com margens salariais inferiores às de seus homólogos europeus nas mesmas categorias. O crescimento demográfico estimulou os processos de marginalização de grupos sociais cada vez mais amplos, plasmado

\footnotetext{
25Um exemplo clássico desta mobilidade se encontra nos jornaleiros temporários do oeste africano (navétans) que se deslocam entre as diferentes colônias britânicas e francesas, gerando conflitos regionais entre ambos os impérios. Veja-se: David (1980).

${ }^{26}$ Sobre este aspecto, veja-se: Thiam (1993).
} 
na constituição do bairro de Medina em 1914, onde as autoridades coloniais instalaram o "distrito africano" que separava espacialmente brancos e negros em Dakar (Seck, 1970, p.131-161).

O incremento demográfico em Dakar respondeu em boa medida aos trabalhos realizados no porto e na cidade. Mão de obra era requerida para executar as grandes obras nas infraestruturas portuárias, mas também nas linhas ferroviárias e no complexo urbanístico em torno da interface marítima. Nesse caso, os peões jornaleiros podiam obter um emprego como carregadores no porto ou então como operários da construção, o que multiplicava suas oportunidades econômicas diante do progressivo estancamento do setor agropecuário de exportação que expulsou milhares de trabalhadores agrários — além dos escravos manumitidos - das zonas rurais. ${ }^{27}$

O impacto sobre o tecido urbano foi evidente. A cidade portuária passou de 3 mil pessoas nos últimos anos da década de 1870 para 8.737 en 1891. Essa dinâmica de crescimento não se deteve nem tem sido detida até a atualidade, representando os problemas estruturais das economias regionais, fundamentados sobretudo na escassa integração dos territórios por causa do modelo econômico extrativo imposto desde a época colonial. Até 1900, a população de Dakar havia crescido para 12 mil pessons, alcançando mais de 23 mil nas vésperas da Primeira Guerra Mundial. A falta de planificação urbana, a escassez de solo disponível (pela própria configuração geográfica da península), o temor europeu às epidemias (febre amarela, cólera) e a revalorização das áreas próximas ao porto estimularam o processo de segregação urbana em Dakar, que se consolidou em 1914 na constituição do quartier africain. O distrito europeu (Plateau) se desenvolveria seguindo os critérios urbanísticos europeus, contando com alguns serviços urbanos básicos e um importante tecido econômico em forma de empresas comerciais, bancos, cafés etc. O bairro branco contava também com um serviço de fornecimento de água potável, esgoto e iluminação que contrastava com a ausência absoluta de todas essas questões em Medina (Faye e Thioub, 2003, p.93-108). Durante os meses de evacuação das produções de amendoins (setembro-dezembro) a chegada a Dakar destes trabalhadores se multiplicava, aproveitando a oportunidade para obter um jornal como estivadores em cais ou na companhia ferroviária. Essa mobilidade e adaptabilidade dos trabalhadores africanos assim como as redes sociais criadas em torno dos residentes en Medina lhes facilitavam a obtenção de jornais suplementares durante estes meses. Não obstante, deve-se assinalar que a chegada massiva de trabalhadores do interior provocava um efeito direto sobre a massa salarial, empurrando os salários para baixo ante o incremento da oferta de mão de obra. Esse fenómeno, somado às crises inflacionárias recorrentes na cidade (especialmente graves durante a Primeira Guerra Mundial), deteriorou notavelmente as condições de vida destes grupos sociais urbanos (Ndao, 2009, p.21-28).

${ }^{27}$ Sobre o processo de proletarização da mão de obra africana, veja-se: Lakroum (1982). 


\section{Crise econômica e metropolização regional de Dakar: os anos 1930}

A crise econômica internacional que se seguiu à crise financeira nova-iorquina em 1929 gerou profundos efeitos de arrasto sobre o conjunto da economia da África Ocidental. A queda da produção industrial na Europa e nos Estados Unidos gerou um descenso na demanda de matérias-primas sobre a qual descansava o tecido produtivo colonial. Se a crise econômica da Grande Guerra havia gerado uma importante deterioração socioeconômica em Dakar e no conjunto do Senegal, a depressão da década de 1930 agravou as carências e debilidades da economia regional.

L'Afrique Occidentale Française entre dans une période difficile. Elle a connu, dans les années qui ont suivi la conclusion de la paix, une ère de prospérité au cours de laquelle le tonnage de la production d'exportation a doublé. La valeur de ces exportations a suivi les fluctuations de la crise monétaire dans la métropole (...) La colonie ne recouvrera une prospérité durable que par une stabilisation des conditions économiques générales. ${ }^{28}$

A queda da demanda em matérias-primas impactou diretamente o valor da produção (situados em valores nominais de 1914), ao que se somaram outros fatores como as bancarrotas entre empresas navegadoras ligadas aos setores industriais metropolitanos..$^{29}$ A queda dos preços dos produtos agrários e a dependência da economia colonial do setor exterior geraram um efeito de arrasto geral que impactou majoritariamente os setores mais vulneráveis: pequenos e médios produtores, jornaleiros e trabalhadores urbanos. A quebra das explorações familiares dedicadas ao cultivo de produtos de exportação assim como a falta de oportunidades no setor agrário incentivaram processos migratórios mais intensos para as cidades portuárias, especialmente Dakar. Outra estratégia utilizada pelos produtores para combater a queda de preços foi elevar as produções agrárias, numa tentativa fútil para aumentar o volume de ingressos nominais. Contudo, essa solução gerou uma maior deterioração no preço recebido por parte dos intermediários já que foi incrementada a oferta de matérias-primas disponíveis - além de outros processos de adulteração como ocorreu no caso do caucho ou da goma arábica. Contudo, a crise marítima (elevação dos fretes) e as dificuldades para colocar essas mercadorias nos mercados ocidentais deprimiram ainda mais os preços das produções agrárias, convertendo-se em uma autêntica tormenta perfeita para a economia senegalesa. A isso se somaram as políticas especulativas das grandes companhias imperiais, que puderam adquirir importantes estoques não perecíveis a baixo custo, incrementando seu domínio sobre o mercado regional. ${ }^{30}$

\footnotetext{
${ }^{28}$ Anom. Affaires Politiques, Carton 2535, 1affpol/532, Informe do Governador Jules Cardé ao Ministério das Colônias, 1930.

${ }^{29}$ Sobre o impacto da crise de 1929 na África Ocidental, veja-se: Daumalin (1992, p.168-218).

30Sobre a atuação das empresas imperialistas durante este período, veja-se: Coquery-Vidrovitch (1975, p.595-621).
} 
Em nível de atividade econômica, o valor nominal das commodities senegalesas caiu em mais de 65\% entre 1928 e 1931, provocando uma profunda crise socioeconômica regional, posto que o custo das importações metropolitanas e do sudeste asiático foi incrementado devido à paralização da indústria e da escassez de fretes. Entre esses produtos cabe destacar o arroz importado do sudeste asiático (Indochina) que conformava uma parte importante da dieta africana - especialmente nos entornos urbanos. Portanto, a crise econômica gerou alguns efeitos de conjunto que revelaram as debilidades estruturais da economia colonial. Durante os anos posteriores à Primeira Guerra Mundial, se havia visibilizado um processo de estancamento do valor das matérias-primas, fundamentado nos parâmetros estabelecidos no "Plano Sarraut" de 1921, que propunha uma recuperação da economia metropolitana sustentada no esforço — econômico e humano - das colônias (Coquery-Vidrovitch, 1979, p.51-76).

Tabela 3 - Indicadores portuários em Dakar (1929-39)

\begin{tabular}{ccccccccc} 
Año & $\begin{array}{c}\text { Buques } \\
\text { entrados* }\end{array}$ & TRB & $\begin{array}{c}\text { Importación } \\
\text { de } \\
\text { mercancía } \\
\text { general }(\mathrm{t})\end{array}$ & $\begin{array}{c}\text { Importación } \\
\text { de } \\
\text { carbón }(\mathrm{t})\end{array}$ & $\begin{array}{c}\text { Suministro } \\
\text { de } \\
\text { carbón }(\mathrm{t})\end{array}$ & $\begin{array}{c}\text { Importación } \\
\text { de fuel-oil } \\
(\mathrm{t})\end{array}$ & $\begin{array}{c}\text { Suministro } \\
\text { de fuel-oil } \\
(\mathrm{t})\end{array}$ & $\begin{array}{c}\text { Exportación } \\
\text { de } \\
\text { cacahuetes } \\
(\mathrm{t})\end{array}$ \\
\hline 1929 & 2.757 & 4.287 .132 & 548.058 & 277.026 & 217.838 & 94.373 & 90.432 & 82.527 \\
1930 & 2.647 & 3.782 .903 & 638.956 & 222.968 & 148.698 & 110.689 & 90.898 & 99.044 \\
1931 & 2.394 & 3.702 .455 & 197.585 & 149.551 & 107.885 & 133.031 & 119.299 & 94.888 \\
1932 & 1.885 & 3.868 .003 & 209.195 & 120.755 & 61.814 & 307.741 & 305.642 & 29.459 \\
1933 & 1.835 & 3.925 .037 & 201.668 & 103.302 & 59.578 & 266.671 & 251.409 & 64.987 \\
1934 & 2.315 & 4.456 .704 & 206.831 & 124.050 & 88.885 & 320.736 & 290.997 & 104.269 \\
1935 & 2.599 & 4.797 .090 & 288.839 & 104.352 & 67.856 & 370.278 & 379.824 & 75.842 \\
1936 & 3.502 & 7.176 .093 & 347.256 & 263.673 & 236.994 & 514.723 & 545.601 & 94.981 \\
1937 & 4.108 & 8.796 .309 & 390.499 & 363.914 & 298.772 & 713.123 & 717.009 & 173.390 \\
1938 & 3.430 & 7.362 .842 & 369.877 & 241.725 & 177.413 & 745.736 & 722.895 & 132.592 \\
1939 & 3.218 & 6.590 .206 & 400.527 & 261.487 & 177.460 & 475.526 & 499.170 & 198.107 \\
\hline
\end{tabular}

Nota: *Excluído o tráfico de cabotagem e pesca.

Fontes: Para 1929-30: Gouvernement Général de l’AOF (1931). Para 1931-39: Anom Carton 363, agefom 84/363. Wittlesey (1941, p.609-638); Bourrières (1948).

No que diz respeito ao desenvolvimento portuário no Senegal, a crise de 1930 impulsionou o processo de metropolização de Dakar como eixo da política imperial francesa na região. Essa década marcou o declínio definitivo de Rufisque como eixo do comércio na colônia em detrimento de Dakar, que absorveu suas funções comerciais. Este processo se consolidou na segunda metade da década, quando todos os indicadores portuários em Dakar iniciaram o caminho da recuperação (tabela 3). Entre esses indicadores, cabe destacar o desenvolvimento do fornecimento de combustíveis líquidos que se havia iniciado nos primeiros anos da década de 1920, como consequência da lenta transição do carvão para o combustível, observando-se um pico de atividade a partir de 1936 em razão do desvio de tráficos dos portos canários devido à eclosão da Guerra Civil Espanhola. A transferência da atividade comercial de Rufisque para Dakar consolidou sua posição hegemônica, agregando definitivamente a função de eixo comercial da colônia às de base logística para a frota francesa. A decisão das instituições coloniais de centralizar a atividade econômica e política em Dakar se realizou após os informes empreendidos pelo inspetor de colônias Edmond Giscard d'Estaing a partir de 1932, observando a necessidade de centralizar as inversões em pontos concretos que funcionariam como polos de desenvolvimento local (Coquery-Vidrovitch, 1979, p.60). 
Por trás de tudo isso se encontrava também a necessidade de incrementar as economias de escala, reduzindo os custos agregados nos portos que beneficiariam a reativação econômica metropolitana.

A configuração de economias externas em Dakar foi um aspecto-chave em sua consolidação como centro econômico do Senegal e do conjunto do AOF. Esse processo implicava a realização de inversões nas infraestruturas, permitindo um desenvolvimento sustentado da atividade marítima que resultasse atrativo para as companhias navais internacionais - especialmente nos tráficos de escala. Na década de 1920 foram levados a cabo diversos projetos de melhora das infraestruturas portuárias (cais comerciais, maior integração intermodal) em previsão da absorção da atividade exportadora de Rufisque. A crise e os novos projetos de centralização das inversões melhoraram a posição de Dakar, eliminando Rufisque da competência interportuária regional. Entre 1934 e 1935 foram concluídas as obras do terminal de amendoins de Dakar (na parte norte do porto) que permitia a rápida evacuação das mercadorias procedentes do interior nos vagões da linha ferroviária, conectada às docas. Nesse período se consolidaram ademais as instalações para o abastecimento de combustível que permitiram acolher um maior número de navios em trânsito. Para tudo isso colaborou a crise portuária das Ilhas Canárias que elevou a atividade no porto senegalês (tabela 3 ). Como exemplo do incremento da importância de Dakar como eixo comercial, cabe destacar a transferência de Rufisque para Dakar em 1933 dos escritórios centrais no AOF da Compagnie Française de l'Afrique Occidentale (CFAO) depois de quase meio século de presença ativa no pequeno porto exportador. ${ }^{31}$

\section{O valor nominal das commodities senegalesas caiu em mais de 65\% entre 1928 e 1931, provocando uma profunda crise socioeconômica regional}

A atividade econômica do porto foi recuperada nos últimos anos da década, em consonância com uma leve melhoria do comércio exterior regional. Contudo, as condições de vida da maior parte da população haviam piorado, incluídas as condições de trabalho (Ndao, 2009, p.129-142). A chegada massiva e desordenada de população rural em busca de sustento devido à deterioração das condições de vida no setor agrícola, a superlotação, o desemprego e a precariedade laboral, incrementou a pobreza e a desigualdade em Dakar (Marie, 1981, p.347-374). O incremento formidável da população estimada na cidade foi um elemento-chave de proletarização das classes populares africanas. ${ }^{32}$

Não obstante, esta questão acelerou os movimentos organizados de resistência por parte destes coletivos, rechaçando a imposição colonial e reclamando um novo pacto social fundamentado na maior igualdade entre europeus e

${ }^{31}$ Para un estudo em profundidade sobre esta empresa, veja-se: Bonin (1987).

32Esta população (estimada) passou das 40 mil pessoas em 1924 a mais de 93 mil em 1936. 
africanos. A crise econômica e a proletarização da mão de obra estimularam o surgimento e o fortalecimento dos movimentos sociais africanos, liderados pelos sindicatos - clandestinos até 1937 - dos setores estratégicos para a economia colonial (portos e ferrovias). ${ }^{33}$ A aglomeração demográfica, o desenvolvimento dos movimentos políticos africanos e as condições socioeconômicas da maior parte destas classes populares incrementaram a conflitividade social em Dakar até a eclosão da Segunda Guerra Mundial (figura 1).

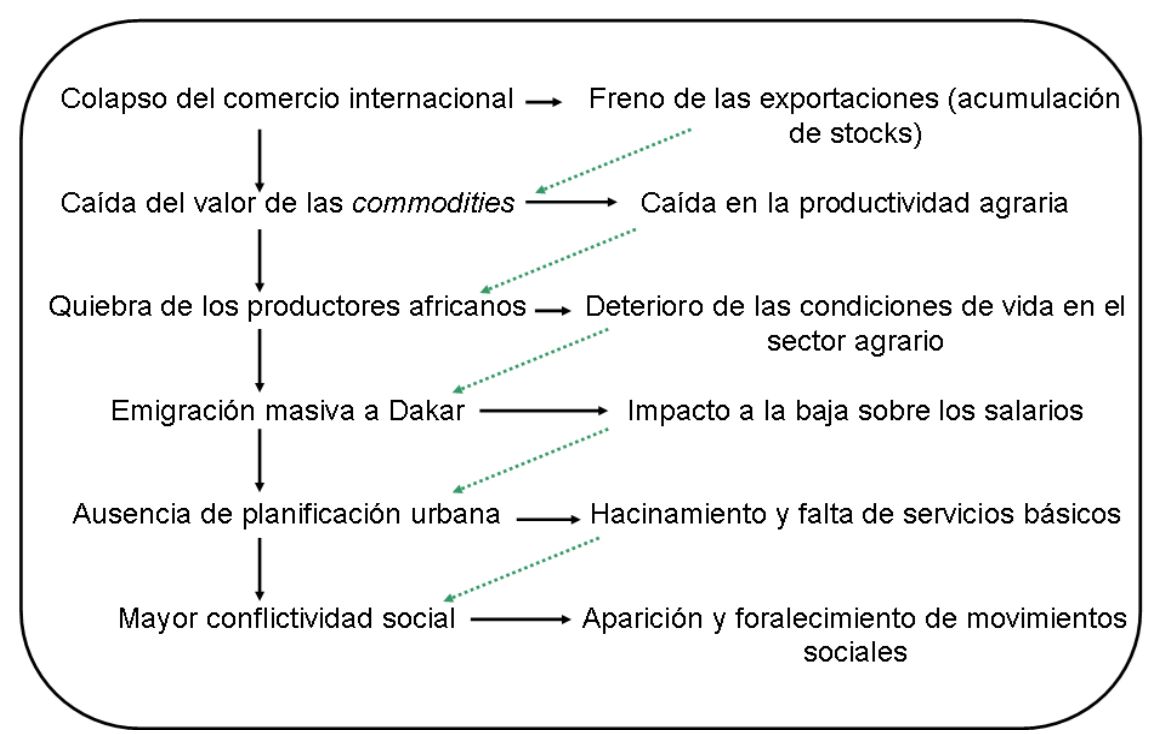

Figura 1: A depressão econômica dos anos 1930 e seu impacto sobre a estrutura socioeconômica senegalesa Fonte: Elaboração própria.

O conflito interrompeu — violentamente - uma projeção de desenvolvimento destes movimentos sociais consolidado durante a Frente Popular quando se legalizaram os sindicatos profissionais no AOF e se produziu um maior equilíbrio nas relações laborais, especialmente nos setores vinculados à atividade comercial. O regime do terror que se impôs com o regime colaboracionista de Vichy implicou um retrocesso do avanço dos direitos laborais e políticos alcançados durante a década de 1930 e que seriam recuperados após o final da guerra.

\section{Conclusões}

A hierarquia portuária senegalesa se constituiu seguindo as necessidades do comércio exterior e o modelo econômico e institucional extrativo colonial. Após a aplicação da reforma portuária no Senegal, o modelo portuário regional passou de ser um modelo relativamente multipolar para um mais centralizado — em Rufisque e Dakar — que acabaria sendo capitalizado por este último.

${ }^{33}$ Sobre os movimentos políticos africanos e a conflitividade social, veja-se: Person (1979, p.77-101). Para uma análise das condições laborais dos trabalhadores africanos durante a crise, consulte-se: D’Almeida-Topor (1976, p.103-117). Acerca das organizações sindicais vinculadas aos transportes, veja-se: Cooper (1990, p.165-215). 
O modelo centro-periferia que caracteriza o sistema capitalista se representou no sistema portuário regional sob estes parâmetros, gerando processos de exclusão e concentração econômica. Em qualquer caso, a ascensão de Dakar na rede portuária regional se deveu também às inversões ocorridas em suas infraestruturas que permitiram um desenvolvimento sustentado e no longo prazo da atividade marítima. Diante da estagnação dos velhos portos de SaintLouis e Gorée, Dakar se impôs como o porto moderno a serviço da navegação de escala no Atlântico Médio, em clara concorrência com os portos cabo-verdianos e canários. O desenho das linhas férreas com destino em Dakar reforçou sua posição regional, incrementando suas funções urbanas.

Este artigo revelou as contradições existentes entre os procesos de crescimento econômico - fundamentados neste caso no comércio exterior - e os problemas estruturais relacionados com o desenvolvimento econômico. Destacou-se em que medida o crescimento do comércio exterior prévio à Primeira Guerra Mundial fundamentado no setor primário excluiu um processo de desenvolvimento econômico no longo prazo devido à natureza extrativa do sistema colonial. Pelo contrário, a própria dinâmica de funcionamento do modelo econômico imperialista agudizou as condições de vida da maior parte da população. No caso de Dakar, o incremento da importância da cidade atraiu um maior número de trabalhadores que conformaram um autêntico exército de reserva de mão de obra com efeitos sobre as políticas salariais e as condições de vida, provocando uma maior marginalidade e desigualdade.

\section{Referências bibliográficas}

ACEMOGLU, Daron; ROBINSON, James. Por quéfracasan los países. Deusto: Deusto Ediciones, 2012.

AMIN, Samir. Más allá del capitalismo senil: por un siglo XXI no norteamericano. Barcelona: El Viejo Topo, 2003.

AYODEJI, Olukoju. The Liverpool of West Africa. The dynamics and impact of maritime trade in Lagos, 1900-1950. Nova Jérsei: Africa World Press, 2004.

BARROWS, Leland C. Faidherbe and Senegal: a critical discussion. African Studies Review, vol. 19, n. 1, p.95-117, 1976.

BARRY, Boubacar. Commerce et commerçants sénégambiens dans la longue durée. Etude d'une formation économique dépendante. In : BARRY, Boubacar; HARDING, Leonhard (Ed.). Commerce et commerçants en Afrique de l'Ouest. Le Sénégal. Paris: L'Harmattan, 1992. p.35-58. BARRY, Boubacar; HARDING, Leonhard (Coord.). Commerce et commerçants en Afrique de l'Ouest. Paris: L'Harmattan, 1992.

BONIN, Hubert. Cent ans de compétition. 1887-1987. Paris: Económica, 1987.

CABRERA ARMAS, Luis Gabriel. The ports of the Canary Islands: the challenges of modernity. In: SUÁREZ BOSA, Miguel (Ed.). Atlantic ports and the First Globalisation, c.1850-1930, Basingstoke: Palgrave MacMillan, 2014. p.19-48.

CASTILLO HIDALGO, Daniel. ¿Vías para el desarrollo económico? El ferrocarril y la expansión de los cultivos de exportación en Senegal, 1880-1918. Transportes, Servicios y Telecomunicaciones, n. 27, p.174-200, 2014a.

CASTILLO HIDALGO, Daniel. The Port of Dakar: Technological Evolution, Managements and Commercial Activity. In: SUÁREZ BOSA, Miguel (Ed.). Atlantic Ports and the First Globalisation, c.1850-1930, Basingtoke: Palgrave MacMillan, 2014b. p.90-111. 
CASTILLO HIDALGO, Daniel. Las puertas del Imperio: análisis del sistema portuario de Senegal. Jerarquía, centralidad y complementariedad en un contexto colonial (1839-1910). Investigaciones de Historia Económica, vol.11, p.91-102, 2015.

CHARPY, Jacques. Dakar: naissance d'une métropole. Rennes: Éditions les Portes du Large, 2007. COOPER, Frederick. The Senegalese Strike of 1946 and the labor question in post-war French Africa. Canadian Journal of African Studies, vol. 24, n. 2, p.165-215, 1990.

COQUERY-VIDROVITCH, Catherine. Colonisation ou impérialisme: la politique africaine de la France entre les deux guerres. Le Mouvement Social, vol. 107, p.51-76, 1979.

COQUERY-VIDROVITCH, Catherine. L'impact des intérêts coloniaux: Scoa et CFAO dans l'ouest africain, 1910-1965. The Journal of African History, vol. 16, n. 4, p.595-621, 1975.

CURRY-MACHADO, John (Ed.). Global histories, imperial commodities, local interactions. Basingstoke: Palgrave MacMillan, 2013.

D'ALMEIDA-TOPOR, Hélène Rechercher sur l'évolution du travail salariçe en AOF pendant la crise économique, 1930-1936. Cahiers d'Études Africaines, vol. 16, n. 61-62, p.103-117, 1976. DAUMALIN, Xavier. Marseille, l'ouest africain et la crise. In: COURDURIE, Marcel; MIÈGE, Jean-Louis (Ed.). Marseille colonial face à la crise de 1929. Marseille: Chambre de Commerce et d'Industrie Marseille-Provence, 1992. p.168-218.

DAVID, Philippe. Les navétanes: histoire des migrants saisonniers de l'arachide en Sénégambie des origines a nos jours. Dakar: Nouvelles Éditions Africaines, 1980.

DEBRIE, Jean. From colonization to national territories in continental West Africa: the historical geography of a transport infrastructure network. Journal of Transport Geography, n. 18, p.292-300, 2010.

DEBRIE, Jean. The West African port system: global insertion and regional particularities., EchoGéo, vol. 20, p.1-10, 2012.

DIOUF, Adama. Fondation du port de Dakar: acteurs et enjeux (1855-1918). Tese (doutorado) - Universidad de Le Havre. Le Havre, 2011.

FALL, Boubacar. Sénégal: le travail au XXème siècle. Dakar: L'Harmattan, 2011.

FAYE, Ousmane; THIOUB, Ibrahima. Les marginaux et l'État à Dakar. Le Mouvement Social, vol. 204, p.93-108, 2003.

HOPKINS, A. G. Economic imperialism in West Africa: Lagos, 1880-1892. The Economic History Review, new series, vol. 21, n. 3, p.580-606, 1969.

HOPKINS, A. G. The new economic history of Africa. Journal of African History, vol. 50, p.155$177,2009$.

LAGRILLIERE-BEAUCLERC, Eugène. Mission au Sénégal et au Soudan. Voyage de M. André Lebon, ministre des Colonies (octobre-novembre 1897). Paris: Chambres de Commerce, 1897. LAKROUM, Monique. Le travail inégal. Paysans et salariés sénégalais face à la crise des années trente, Paris: L'Harmattan, 1982.

LAPRADE, Pinet (entrevista). Les Colonies Françaises. La Revue Coloniale, Paris, Imprimerie et Librairie Administrative de Paul Dupont, p.10-11, 1857.

LES COLONIES FRANÇAISES, le Sénégal. Exposition Universelle de 1900. Paris : Librairie Maritime et Coloniale, 1900.

MARIE, Alain. Marginalité et conditions sociales du prolétariat urbain en Afrique. Les approches de concept de marginalité et son évaluation critique. Cahiers d'Études Africaines, vol. 21, n. 81-83, p.347-374, 1981.

MARNOT, Bruno. Les grands ports de commerce français et la mondialisation du XIXe siècle. Paris: Presses Universitaires Paris-Sorbonne, 2011.

MOHAMED-CHÉRIF, Fatima Zohra; DUCRUET, César. Les ports et la façade maritime du Maghreb, entre intégration régionale et mondiale. M@appemonde, n. 101, 2011. Disponível em: http://mappemonde.mgm.fr/num29/articles/art11103.html.

MOITT, Bernard. Slavery and emancipation in Senegal's peanut basin: the nineteenth and twentieth centuries. The International Journal of African Historical Studies, vol. 22, n. 1, p.27-50, 1992. MORAZÉ, Charles. Dakar. Annales de Géographie, vol. 45, n.258, p.607-631, 1936.

NDAO, Mor. Le ravitaillement de Dakar de 1914 a 1945. Dakar: L'Harmattan, 2009. p.21-28. PERSON, Yves. Le Front Populaire au Sénégal (mai 1936-octobre 1938). Le Mouvement Social, vol. 107, p.77-101, 1979. 
PETEREC, Richard J. Dakar and West African economic development. Nova York: Columbia University Press, 1967.

POLÓNIA, Amèlia. European seaports in the Early Modern Age: concepts, methodology and models of analysis. Cahiers de la Méditerranée, n. 80, p.17-39, 2010.

PRASHAD, Vijay. The poorer nations: a possible history of the global south. Londres: Verso Books, 2013.

RAMBAUD, Alfred. La France coloniale, histoire, géographie, commerce. 6. ed. Paris: Armand Colin et Cie. Editeurs, 1893 [1. ed. de 1895].

RODNEY, Walter. How Europe underdeveloped Africa. Dakar: Pambazuuka Editions, 2011 [1. ed. de 1971].

SECK, Assane. Dakar, métropole Ouest-Africaine. Dakar: Mémoires de l'Ifan, 1970.

SILVA, Antonio Leão Aguiar de Correia e. Nos tempos do Porto Grande de Mindelo. Praia, Mindelo: Centro Cultural do Mindelo, 2000.

SILVA, Antonio Leão Aguiar de Correia e. Os ciclos históricos da inserção de Cabo Verde na economia atlântica: o caso das cidades de Riberia Grande e Mindelo. Tese (doutorado) —— Faculdade de Ciencias Sociais e Humanas da Universidade Nova de Lisboa. Lisboa, 2007.

STIGLITZ, Joseph. El malestar en la globalización. Buenos Aires: Taurus, 2002.

SUÁREZ BOSA, Miguel (Ed.). Atlantic ports and the First Globalisation, c. 1850-1930. Basingstoke: Palgrave MacMillan, 2014.

SUÁREZ BOSA, Miguel; CABRERA ARMAS, Luis Gabriel. La competencia en los servicios portuarios entre Cabo Verde y Canarias (1850-1914). Anuario de Estudios Atlánticos, vol. 58, p.363414, 2012.

THIAM, Iba Der. Histoire du mouvement syndical africain, 1790-1929. Paris: L'Harmattan, 1993. THOMAS, Benjamin. Railways and Ports in French West Africa. Economic Geography, vol. 33, n. 1, p.1-15, 1957. 